\title{
Principles of process modeling of the heat supply systems operation
}

\author{
Anna Doroshenko ${ }^{1, *}$ and Anastasiya Yusupova ${ }^{1}$ \\ ${ }^{1}$ Moscow State University of Civil Engineering, Yaroslavskoe shosse, 26, Moscow, 129337, Russia
}

\begin{abstract}
The problem of process modeling of heat supply systems operation with the appropriate of the special software is presented in the article. The purpose of the simulation is to identify the most likely and dangerous accidents, the quantitative and qualitative assessment of them, the frequency of their occurrence, the size of the damage, etc. The implementation of the solution presented in the work is already useful at present to improve the design and further operation of heat supply systems, and as a consequence also for consumers of thermal energy. The use of simulated modeling of heat supply system operation processes significantly reduces the strength calculation time, allows simulating various pipeline route configurations, performing their comparative analysis, and choosing optimal characteristics for the simulated system.
\end{abstract}

\section{Introduction}

Modern heat supply is nothing more than a complex energy economy, whose main task is to provide consumers with enough heat. Accident-free operation of equipment, heat sources, networks and subscriber inputs, ensuring uninterrupted heat supply, depends on each element of this economy, starting with the designers and ending with the operating organization. It is believed that the greatest responsibility lies with the operating organization, because it is obliged to carry out technical supervision of the site at the design, construction, start-up and adjustment stages of heat supply systems, monitor heat release regimes and develop them, provide timely repair of network equipment, continuously improve the technical and economic performance of all elements of the economy [1-13].

Annually with the beginning of a new heating season, numerous reports of violations in the life support systems of the population come. Statistics show a high dynamics of growth in the total number of accidents, affected areas and groups of citizens. The emergency stoppage of heating stops the operation of production processes and worsens the comfortable living conditions of people. The main causes of accidents in heat supply systems are:

- high percentage of obsolete equipment;

- damage to pipelines and poor quality of thermal insulation;

- defects in the installation of pipelines and equipment;

* Corresponding author: pochta.avd@gmail.com 
- errors at the design stage of heat networks and calculation of their strength, etc .

To eliminate accidents, every year large material resources are expended. New, reconstructed and repaired heating systems can for a long time not exhibit hidden defects that could cause an accident. From this it follows that the emergency prevention must first of all be in the timely detection of the centers of destruction.

The same external and internal influences often lead to different, and sometimes even opposite, results. It depends on the state in which the system was at the time of the impact. To anticipate the reaction of the system to the action of various factors, one can only carry out a complex analysis of the relationships and regularities existing in it.

\section{Methods}

Modern science has not yet learned how to perform calculations for the strength of real pipelines. Therefore, modeling became widespread [1, 2, 3, 7, 13].

Modeling is a method of solving set problems, in which the research system is replaced by a simpler object that describes the real model, and is called a computational model.

The purpose of the simulation is to identify the most likely and dangerous accidents, the quantitative and qualitative assessment of them, the frequency of their occurrence, the size of the damage, etc. Based on the results of computer simulation, it is possible to conclude how likely the emergency shutdown of heat supply, which preconditions have the most significant effect on this probability.

When calculating pipelines using modern software systems, engineers have to work with a design scheme - a computer model, and not with a real pipeline design. The need to apply the design model is due to the fact that it is impossible to take into account all the properties of the construction of a real pipeline.

A computational model is a computer program describing the construction and recreating behavior of a real system over time. It gives an opportunity to present in detail the operation of the system during its operation.

At present, numerous programs are designed to calculate the strength and rigidity of pipelines for various purposes under static and cyclic loading. In such programs are calculated as pipelines in which compensation of temperature extensions in the operating mode is provided by the flexibility of the route of the heating network itself, and pipelines whose compensation for temperature expansion is due to special compensating devices made in the form of compensators.

The software system can be used both to solve various problems in the field of research related to the refinement of calculation schemes, as well as to study the real operating conditions of pipelines, and to perform mass calculations, etc.

Idealization of the geometric image of the pipeline when specifying the design model is one of the most common mistakes. The pipeline image in the working drawings is usually schematic in one, sometimes in two lines, with the dimensioning to its center line. Elements of the pipeline, such as bends, transitions, tees, fittings, etc., are usually represented by conventional signs. An engineer with insufficient experience in performing calculations usually considers his task to accurately reproduce the drawing on the computer screen. In this case, the existence of a large difference between the drawing of the pipeline and its design model is lost sight of.

A pipeline drawing is a conditional representation of a real pipeline design. In turn, the design model is an idealized pipeline scheme, freed from features that are insignificant from the design point of view.

So what are the main criteria for choosing a design model?

The design model should: 
- proceed from the possible form of destruction and deformation of the pipeline structure, reinforced by practical experience;

- correctly and qualitatively display the elastic behavior of the structure under load,

- to place the pipeline design in less favorable conditions than those that may actually be present (to provide safety reserves),

- do not go beyond the limitations of the theory that is used to solve the task.

For the same real design, several calculation models can be selected, depending on which side of the pipeline operation is of interest to the project developer $[1,7]$.

\section{Calculation}

The calculation was carried out in the START software package, product version 04.82 R3. Normative document for the evaluation of strength: RD 10-400-01 Thermal networks.

The calculation was carried out for pipelines of the route of the heating network 2Dn159x5 in PPU-PE insulation with DN160 diameter. The length of the route is $318.7 \mathrm{~m}$.

The service life of the pipeline is 30 years. The calculated water temperature is $130^{\circ} \mathrm{C}$, the design pressure is $16 \mathrm{kgf} / \mathrm{cm}^{2}$, the welded joint strength factor is 1.0 , the coefficient of strength of the transverse welded joint is 0.9 , the corrosion is added to the thickness of 0.9 $\mathrm{mm}$.

In the design model 2945 nodes were accepted, including the fastening and equipment nodes (expansion joints, sliding supports, fixed supports, fittings, bends).

Long track locations are "broken" into nodes to be read for strength and cyclic stability over the entire length of the pipeline.

The calculation was carried out for all pipeline conditions (installation, operating, cold, test condition).

The pipeline was considered as a core system consisting of straight (pipe, fittings) and curved rods (bends).

Bellows expansion joints are used in the thermal chamber of network (Figure 1), to compensate temperature expansion.

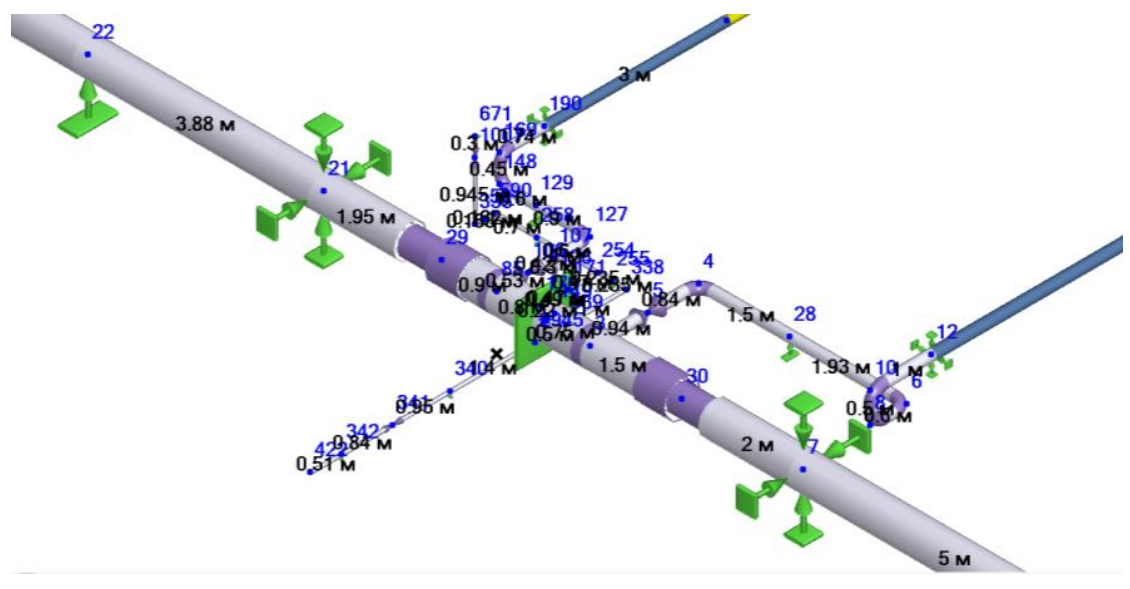

Fig.1. Thermal network camera model.

The stages of the calculations were as follows:

- determination of the direction of the route of the heat network and the way it is laid;

- determination of the computational model in the program complex;

- calculation of the stresses of the pipelines of the heating network;

- calculation of loads on fastenings and equipment of pipelines of a thermal network; 
- calculation of heat network pipelines for movement; calculation of the deformation of the compensation equipment (if any);

- analysis of the results of the calculation performed;

- changing the configuration of the heating network pipelines (if necessary);

- recalculation of the required parameters of the heating network pipelines.

\section{Results}

As a result of the calculation, it was revealed that the chosen configuration of the pipeline lines does not meet the requirements for strength conditions. Such a conclusion was made on the basis of the calculation of the pipeline stresses.

In the operating conditions of the heat network, some of its elements appear damaged. The cause of damage in sections 3, 339, 340, 341 is the failure of the strength conditions from the weight in working order, and in section 131 - the strength conditions from all impacts in working order (table 1).

Table 1. Stresses in the pipeline (fragment)

\begin{tabular}{|c|c|c|c|c|c|c|c|}
\hline \multirow[t]{2}{*}{ Element } & \multirow[t]{2}{*}{$\begin{array}{l}\text { Starting } \\
\text { node; } \\
\text { End } \\
\text { node }\end{array}$} & \multicolumn{2}{|c|}{$\begin{array}{c}\text { Stress from the } \\
\text { weight load in } \\
\text { working condition, } \\
\mathrm{kgf} / \mathrm{cm} 2\end{array}$} & \multicolumn{2}{|c|}{$\begin{array}{c}\text { Stress from all } \\
\text { influences in } \\
\text { working condition, } \\
\mathrm{kgf} / \mathrm{cm} 2\end{array}$} & \multicolumn{2}{|c|}{$\begin{array}{c}\text { Stress from all } \\
\text { influences in the cold } \\
\text { state, } \mathrm{kgf} / \mathrm{cm} 2\end{array}$} \\
\hline & & estimated & allowed & estimated & allowed & estimated & allowed \\
\hline $\begin{array}{l}\text { seam- } \\
\text { welded }\end{array}$ & 3 & 1677.86 & 1593.9 & 1835.08 & not & 1629.85 & not \\
\hline \multirow[t]{2}{*}{ air segment } & 338 & 243.61 & 1617 & 194.92 & 2205 & 199 & 2205 \\
\hline & 339 & 2852.36 & 1617 & 2857.55 & 2205 & 2810.35 & 2205 \\
\hline \multirow[t]{2}{*}{ air segment } & 339 & 2847.68 & 1617 & 2867.86 & 2205 & 2815.96 & 2205 \\
\hline & 2945 & 907.44 & 1617 & 926.52 & 2205 & 875.94 & 2205 \\
\hline \multirow[t]{2}{*}{ air segment } & 2945 & 907.44 & 1617 & 926.52 & 2205 & 875.94 & 2205 \\
\hline & 340 & 2025.36 & 1617 & 2031 & 2205 & 1995.92 & 2205 \\
\hline \multirow[t]{2}{*}{ air segment } & 340 & 2025.36 & 1617 & 2031 & 2205 & 1995.92 & 2205 \\
\hline & 341 & 1920.63 & 1617 & 1928.39 & 2205 & 1890.84 & 2205 \\
\hline \multirow{2}{*}{$\begin{array}{c}\text { underground } \\
\text { segment }\end{array}$} & 61 & 345.20 & 1593.90 & 1886.75 & 2173.5 & 986.86 & 2205 \\
\hline & 131 & 345.19 & 1593.90 & 3361.87 & 2173.5 & 1299.92 & 2205 \\
\hline $\begin{array}{c}\text { sharply- } \\
\text { curved bend }\end{array}$ & 131 & 228.37 & 1593.90 & 5086.91 & not & 2495.94 & not \\
\hline \multirow{2}{*}{$\begin{array}{l}\text { underground } \\
\text { segment }\end{array}$} & 131 & 345.19 & 1593.90 & 3579.64 & 2173.5 & 1657.98 & 2205 \\
\hline & 133 & 345.19 & 1593.90 & 673.43 & 2173.5 & 565.37 & 2205 \\
\hline
\end{tabular}

In order to eliminate the damages in sections $3,339,340,341$, on the existing heat network route, additional sliding supports must be installed during the reconstruction, which will take on the weight of the working pipelines. In section 131, it is necessary to change the gasket type from underground to non-channel, to the gasket in the passageway on the sliding supports. This solution allowed to remove soil pressure on the pipeline and compensate for temperature expansion during pipeline operation.

Based on these results, it is evident that the damageability of elements in the working pipeline of the heating system has been eliminated. The absence of damage in the 
calculation allows us to conclude that the heat network is ready for operation, as well as minimization of emergency situations during the operation of the heat network.

Table 2. Stresses in the pipeline (fragment)

\begin{tabular}{|c|c|c|c|c|c|c|c|}
\hline \multirow[t]{2}{*}{ Element } & \multirow[t]{2}{*}{$\begin{array}{l}\text { Starting } \\
\text { node; } \\
\text { End } \\
\text { node }\end{array}$} & \multicolumn{2}{|c|}{$\begin{array}{c}\text { Stress from the } \\
\text { weight load in } \\
\text { working condition, } \\
\mathrm{kgf} / \mathrm{cm} 2\end{array}$} & \multicolumn{2}{|c|}{$\begin{array}{c}\text { Stress from all } \\
\text { influences in } \\
\text { working condition, } \\
\mathrm{kgf} / \mathrm{cm} 2\end{array}$} & \multicolumn{2}{|c|}{$\begin{array}{c}\text { Stress from all } \\
\text { influences in the } \\
\text { cold state, } \mathrm{kgf} / \mathrm{cm} 2\end{array}$} \\
\hline & & estimated & allowed & estimated & allowed & estimated & allowed \\
\hline $\begin{array}{c}\text { seam- } \\
\text { welded }\end{array}$ & 3 & 450.06 & 1593.90 & 899.47 & not & 689.78 & not \\
\hline \multirow[t]{2}{*}{ air segment } & 338 & 82 & 1617 & 163.80 & 2205 & 114.83 & 2205 \\
\hline & 339 & 471.46 & 1617 & 487.67 & 2205 & 438.28 & 2205 \\
\hline \multirow[t]{2}{*}{ air segment } & 339 & 471.46 & 1617 & 497.35 & 2205 & 447.97 & 2205 \\
\hline & 2945 & 229.14 & 1617 & 244.94 & 2205 & 206.36 & 2205 \\
\hline \multirow[t]{2}{*}{ air segment } & 2945 & 229.14 & 1617 & 244.94 & 2205 & 206.36 & 2205 \\
\hline & 340 & 711.76 & 1617 & 727.45 & 2205 & 688.39 & 2205 \\
\hline \multirow[t]{2}{*}{ air segment } & 340 & 711.77 & 1617 & 717.95 & 2205 & 679.12 & 2205 \\
\hline & 341 & 481.22 & 1617 & 489.96 & 2205 & 448.38 & 2205 \\
\hline \multirow{2}{*}{$\begin{array}{c}\text { underground } \\
\text { segment }\end{array}$} & 61 & 246.43 & 1593.90 & 246.46 & 2173.5 & 81.94 & 2205 \\
\hline & 131 & 246.41 & 1593.90 & 605.46 & 2173.5 & 110.14 & 2205 \\
\hline $\begin{array}{c}\text { sharply- } \\
\text { curved bend }\end{array}$ & 131 & 173.72 & 1593.90 & 873.24 & not & 184.35 & not \\
\hline \multirow{2}{*}{$\begin{array}{c}\text { underground } \\
\text { segment }\end{array}$} & 246.40 & 1593.90 & 644.20 & 2173.50 & 117.73 & 2205 & 246.40 \\
\hline & 246.41 & 1593.90 & 507.40 & 2173.50 & 98.76 & 2205 & 246.41 \\
\hline
\end{tabular}

\section{Conclusions}

The problem is topical for today. The solution of this problem is connected with the timely detection of the preconditions of an emergency situation of the heat network.

The implementation of the solution presented in the work is already useful at present to improve the design and further operation of heat supply systems, and as a consequence also for consumers of thermal energy.

The use of simulated modeling of heat supply system operation processes significantly reduces the strength calculation time, allows simulating various pipeline route configurations, performing their comparative analysis, and choosing optimal characteristics for the simulated system.

This work was financially supported by Ministry of Education and Science of the Russian Federation (\#NSh-3492.2018.8).

\section{References}

1. A. Dalla Rosa, H. Li, S. Svendsen, Heat Transfer Engineering, 34 (4), 372 (2013)

2. V.A. Stennikov, I.V. Postnikov, Power Technology and Engineering, 47 (6) 446, (2014) 
3. G.V. Kuznetsov, V.Yu. Polovnikov, Journal of Engineering Physics and Thermophysics, 81 (2), 323 (2008)

4. V.E. Bukhin, Teploenergetika, (4), 24 (2002)

5. V.V. Tokarev, Z.I. Shalaginova, Thermal Engineering (English translation of Teploenergetika), 63 (1), 68 (2016)

6. L.S. Popyrin, A.N. Zubets, M.D. Dil'man, Izvestiya Akademii Nauk. Energetika, (1), 34 (1995)

7. V.A. Stennikov, E.E. Mednikova, Thermal Engineering, 63 (9), 657 (2016)

8. A.S. Nekrasov, Y.V. Sinyak, S.A. Voronina, Studies on Russian Economic Development, 22 (2), 130 (2011)

9. H. Yamaguchi, H. Morita, H. Asano, Y. Hisasumi, Nihon Kikai Gakkai Ronbunshu, B Hen/Transactions of the Japan Society of Mechanical Engineers, Part B, 76 (772), 2203 (2010)

10. N. Makisha, Procedia Engineering, 165, 1087 (2016)

11. N. Makisha, E3S Web of Conferences, 6, 01002 (2016)

12. R.F. Ganiev, S.R. Ganiev, V.P. Kasilov, A.P. Pustovgar, Wave Technology in Mechanical Engineering: Industrial Applications of Wave and Oscillation Phenomena, (Wiley, 2015)

13. Z.G. Ter-Martirosyan, A.Z. Ter-Martirosyan, Soil Mechanics and Foundation Engineering, 51 (6), pp. 273-281. (2015) 